Kong Mun Lo, See Mun Lee, Peter J. Heard and Edward R.T. Tiekink*

\title{
Crystal structure of hexacarbonyl-bis $\left(\mu_{2}\right.$-di-n- propyldithiocarbamato- $\left.\mathrm{K}^{3} S, S^{\prime}: S ; \mathrm{K}^{3} S: S: S^{\prime}\right)$-di- rhenium(I), $\mathrm{C}_{20} \mathrm{H}_{28} \mathrm{~N}_{2} \mathrm{O}_{6} \mathrm{Re}_{2} \mathrm{~S}_{4}$
}

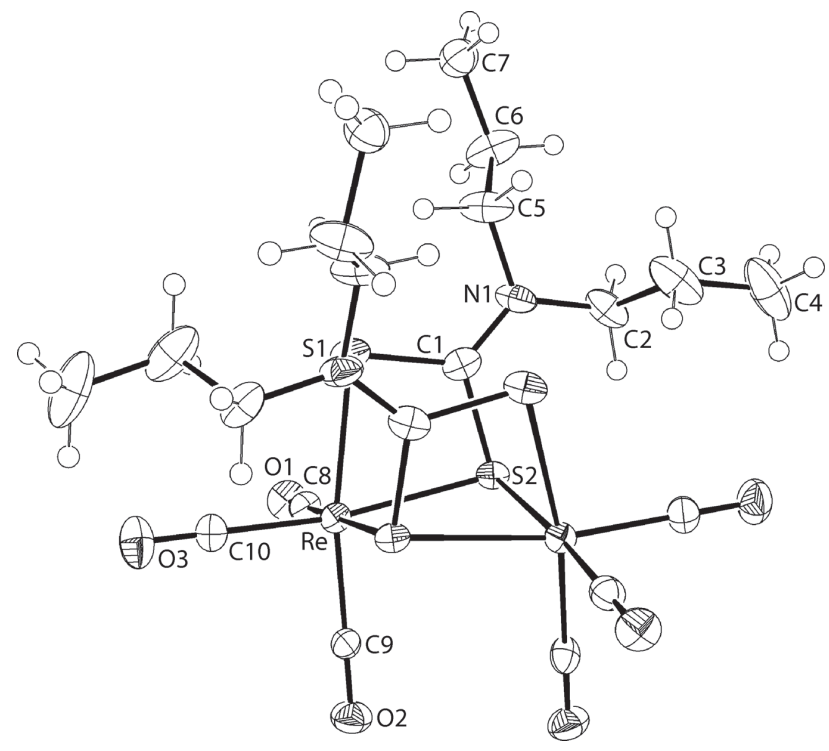

https://doi.org/10.1515/ncrs-2019-0494

Received July 14, 2019; accepted August 5, 2019; available online August 23, 2019

\begin{abstract}
$\mathrm{C}_{20} \mathrm{H}_{28} \mathrm{~N}_{2} \mathrm{O}_{6} \mathrm{Re}_{2} \mathrm{~S}_{4}$, monoclinic, $C 2 / c$ (no. 15), $a=17.9296(4) \AA$, $b=9.60120(10) \AA, \quad c=16.1859(3) \AA, \quad \beta=103.934(2)^{\circ}$, $V=2704.34(9) \AA^{3}, Z=4, R_{\mathrm{gt}}(F)=0.0336, w R_{\mathrm{ref}}\left(F^{2}\right)=0.0902$, $T=100 \mathrm{~K}$.
\end{abstract}

CCDC no.: 1945348

The molecular structure is shown in the figure. Table 1 contains crystallographic data and Table 2 contains the list of the atoms including atomic coordinates and displacement parameters.

\footnotetext{
*Corresponding author: Edward R.T. Tiekink, Research Centre for Crystalline Materials, School of Science and Technology, Sunway University, 47500 Bandar Sunway, Selangor Darul Ehsan, Malaysia, e-mail: edwardt@sunway.edu.my. https://orcid.org/0000-0003-1401-1520

Kong Mun Lo and See Mun Lee: Research Centre for Crystalline Materials, School of Science and Technology, Sunway University, 47500 Bandar Sunway, Selangor Darul Ehsan, Malaysia

Peter J. Heard: Office of the Provost, Sunway University, 47500 Bandar Sunway, Selangor Darul Ehsan, Malaysia
}

Table 1: Data collection and handling.

\begin{tabular}{|c|c|}
\hline Crystal: & Brown prism \\
\hline Size: & $0.09 \times 0.07 \times 0.04 \mathrm{~mm}$ \\
\hline Wavelength: & Cu $K \alpha$ radiation $(1.54184 \AA$ \\
\hline$\mu:$ & $20.5 \mathrm{~mm}^{-1}$ \\
\hline Diffractometer, scan mode: & XtaLAB Synergy, $\omega$ \\
\hline$\theta_{\max }$, completeness: & $67.1^{\circ},>99 \%$ \\
\hline$N(h k l)_{\text {measured }}, N(h k l)_{\text {unique }}, R_{\text {int }}:$ & $31700,2420,0.046$ \\
\hline Criterion for $I_{\mathrm{obs}}, N\left(h k l_{\mathrm{gt}}\right.$ : & $I_{\text {obs }}>2 \sigma\left(I_{\text {obs }}\right), 2402$ \\
\hline$N(\text { param })_{\text {refined }}:$ & 156 \\
\hline Programs: & $\begin{array}{l}\text { CrysAlis }{ }^{P R O}[1], \text { SHELX }[2,3] \text {, } \\
\text { WinGX/ORTEP [4] }\end{array}$ \\
\hline
\end{tabular}

\section{Source of material}

All chemicals and solvents were used as purchased without purification. The melting point was determined using a Melttemp II digital melting point apparatus and was uncorrected. The solid-state IR spectrum was obtained on a Bruker Vertex 70v FTIR Spectrometer from 4000 to $400 \mathrm{~cm}^{-1}$. The ${ }^{1} \mathrm{H}$ and ${ }^{13} \mathrm{C}\left\{{ }^{1} \mathrm{H}\right\}$ NMR spectra were recorded at room temperature in DMSO- $\mathrm{d}_{6}$ solution on a Bruker Ascend $400 \mathrm{MHz}$ NMR spectrometer with chemical shifts relative to tetramethylsilane.

Bromopentacarbonylrhenium was prepared from the reaction of a 1:1 molar ratio of $\mathrm{Re}_{2}(\mathrm{CO})_{10}$ (Merck) and $\mathrm{Br}_{2}$ (Panreac) in dichloromethane at $273 \mathrm{~K}$. White solids were obtained from the slow evaporation of the solvent. The solids were recrystallised in acetone prior to use. The dithiocarbamate ligand was prepared in situ (acetone) from the reaction of $\mathrm{CS}_{2}$ (Panreac $0.25 \mathrm{mmol}$ ) with di- $n$-propylamine (Merck, $0.25 \mathrm{mmol})$ and $\mathrm{NaOH}(0.02 \mathrm{~mL} ; 50 \% \mathrm{w} / \mathrm{v}) ; \mathrm{CS}_{2}$ was added dropwise to the acetone solution $(15 \mathrm{~mL})$. The resulting mixture solution was kept at $273 \mathrm{~K}$ for $0.5 \mathrm{~h}$. Bromopentacarbonylrhenium(I) $(0.25 \mathrm{mmol}, 0.102 \mathrm{~g})$ in acetone $(10 \mathrm{~mL})$ was added to the solution containing the prepared sodium di- $n$ propyldithiocarbamate salt. The resulting mixture was stirred under reflux for $2 \mathrm{~h}$. The filtrate was evaporated slowly until a light-brown precipitate was obtained. The precipitate was recrystallised from acetone-dichloromethane by slow evaporation to yield light-brown crystals. Yield: 0.15 g, 67.2\%; M.pt: 425-427 K. IR $\left(\mathrm{cm}^{-1}\right)$ : 2006 (s) v(CO), 1879(vs, br) v(CO), 
Table 2: Fractional atomic coordinates and isotropic or equivalent isotropic displacement parameters $\left(\AA^{2}\right)$.

\begin{tabular}{lrrrr}
\hline Atom & $\boldsymbol{x}$ & $\boldsymbol{y}$ & $\boldsymbol{z}$ & $\boldsymbol{U}_{\text {iso }}{ }^{*} \boldsymbol{U}_{\text {eq }}$ \\
\hline Re & $0.50575(2)$ & $0.18792(3)$ & $0.13502(2)$ & $0.02114(13)$ \\
S1 & $0.54197(9)$ & $0.43843(17)$ & $0.15283(11)$ & $0.0274(3)$ \\
S2 & $0.59562(8)$ & $0.22353(16)$ & $0.27875(10)$ & $0.0211(3)$ \\
O1 & $0.6337(3)$ & $0.1362(6)$ & $0.0427(3)$ & $0.0338(11)$ \\
O2 & $0.4825(3)$ & $-0.1287(5)$ & $0.1425(3)$ & $0.0353(11)$ \\
O3 & $0.3869(3)$ & $0.1967(6)$ & $-0.0367(3)$ & $0.0417(14)$ \\
N1 & $0.6350(3)$ & $0.4966(6)$ & $0.3056(4)$ & $0.0308(13)$ \\
C1 & $0.5970(4)$ & $0.4037(7)$ & $0.2538(4)$ & $0.0268(14)$ \\
C2 & $0.6847(4)$ & $0.4637(8)$ & $0.3886(5)$ & $0.0337(16)$ \\
H2A & 0.737041 & 0.498279 & 0.390171 & $0.040^{*}$ \\
H2B & 0.687814 & 0.361175 & 0.394820 & $0.040^{*}$ \\
C3 & $0.6596(5)$ & $0.5234(11)$ & $0.4635(6)$ & $0.053(2)$ \\
H3A & 0.654213 & 0.625675 & 0.456992 & $0.063^{*}$ \\
H3B & 0.608815 & 0.484558 & 0.465054 & $0.063^{*}$ \\
C4 & $0.7171(5)$ & $0.4901(14)$ & $0.5462(6)$ & $0.066(3)$ \\
H4A & 0.767752 & 0.525795 & 0.544055 & $0.099^{*}$ \\
H4B & 0.719949 & 0.388918 & 0.554583 & $0.099^{*}$ \\
H4C & 0.700686 & 0.533870 & 0.593645 & $0.099^{*}$ \\
C5 & $0.6282(4)$ & $0.6459(8)$ & $0.2820(6)$ & $0.0392(19)$ \\
H5A & 0.590901 & 0.654918 & 0.226209 & $0.047^{*}$ \\
H5B & 0.606751 & 0.696256 & 0.324433 & $0.047^{*}$ \\
C6 & $0.7005(5)$ & $0.7149(8)$ & $0.2765(6)$ & $0.044(2)$ \\
H6A & 0.722902 & 0.665525 & 0.234553 & $0.052^{*}$ \\
H6B & 0.737793 & 0.710208 & 0.332566 & $0.052^{*}$ \\
C7 & $0.6861(5)$ & $0.8661(8)$ & $0.2501(5)$ & $0.0375(17)$ \\
H7A & 0.654287 & 0.870488 & 0.191693 & $0.056^{*}$ \\
H7B & 0.735312 & 0.912592 & 0.252843 & $0.056^{*}$ \\
H7C & 0.659484 & 0.912759 & 0.288556 & $0.056^{*}$ \\
C8 & $0.5850(4)$ & $0.1559(7)$ & $0.0780(4)$ & $0.0266(14)$ \\
C9 & $0.4904(4)$ & $-0.0111(7)$ & $0.1402(4)$ & $0.0249(13)$ \\
C10 & $0.4312(4)$ & $0.1938(7)$ & $0.0269(4)$ & $0.0272(15)$ \\
\hline & & & &
\end{tabular}

1615(s) v(CN), 1087 (m) v(CS), 898 (m) v(CS). ${ }^{1}$ H NMR (DMSO$\left.\mathrm{d}_{6}\right): \delta$ 0.87-0.93 (m, 3H, $\left.\mathrm{CH}_{3}\right), 1.68-1.70\left(\mathrm{~m}, 2 \mathrm{H}, \mathrm{CH}_{2}\right), 3.56-3.60$ (m, 2H, NCH $\left.{ }_{2}\right){ }^{13} \mathbf{C}\left\{{ }^{1} \mathbf{H}\right\}$ NMR (DMSO-d $\left.\mathrm{d}_{6}\right): \delta 11.5\left(\mathrm{CH}_{3}\right), 20.5$ $\left(\mathrm{CH}_{2}\right), 50.9\left(\mathrm{CH}_{2} \mathrm{~N}\right), 195.9\left(\mathrm{CS}_{2}\right), 196.1,200.8,213.3(\mathrm{CO})$.

\section{Experimental details}

The $\mathrm{C}$-bound $\mathrm{H}$ atoms were geometrically placed ( $\mathrm{C}-$ $\mathrm{H}=0.98-0.99 \AA)$ and refined as riding with $U_{\text {iso }}(\mathrm{H})=1.2-$ $1.5 U_{\text {eq }}(\mathrm{C})$. The maximum and minimum residual electron


located 0.91 and $0.86 \AA$ from the Re atom, respectively.

\section{Comment}

Full characterisation by X-ray crystallography of binuclear molecules of the general formula $\left\{(\mathrm{CO})_{3} \operatorname{Re}\left[\mathrm{S}_{2} \mathrm{CNR}_{2}\right]\right\}_{2}$ is available for $\mathrm{R}=\mathrm{Et}$ [5], $\mathrm{n}-\mathrm{Bu}$ [6] and $\mathrm{CH}_{2} \mathrm{C}(=\mathrm{O}) \mathrm{OH}$ [7]. The interesting feature of these structures is the observed syn-disposition of the dithiocarbamate groups, a feature quite distinct from that generally found in the far more numerous zinc-triad structures of general formula $\left\{\mathrm{M}\left[\mathrm{S}_{2} \mathrm{CNR}_{2}\right]_{2}\right\}_{2}$ whereby antidispositions are the norm [8]. The syn-dispositions in the rhenium(I) complexes raise the possibility of stabilising intramolecular $\pi$ (chelate) $\cdots \pi$ (chelate) interactions $[9,10]$. The X-ray crystallographic analysis of the title complex, $\left\{(\mathrm{CO})_{3} \operatorname{Re}\left[\mathrm{S}_{2} \mathrm{CN}(\mathrm{n}-\mathrm{Pr})_{2}\right]\right\}_{2}$, was undertaken as part of on-going structural studies in this area.

The binuclear molecule of two-fold symmetric $\left\{\operatorname{Re}\left[\mathrm{S}_{2} \mathrm{CN}(\mathrm{n}-\mathrm{Pr})\right](\mathrm{CO})_{3}\right\}_{2}$ is shown in the figure $(50 \%$ displacement ellipsoids; unlabelled atoms are related by the symmetry operation (i): $1-x, y, 1 / 2-z$ ). The independent $\mu_{2}$-bridging dithiocarbamate ligand chelates one rhenium(I) atom with similar $\mathrm{Re}-\mathrm{S}$ bond lengths, i.e. Re$\mathrm{S} 1=2.4898(16) \AA$ and $\mathrm{Re}-\mathrm{S} 2=2.5140(15) \AA$, while simultaneously bonding to the symmetry-related rhenium atom via one sulphur atom at a somewhat longer $\mathrm{Re}-\mathrm{S} 2^{\mathrm{i}}$ bond length of 2.5671(15) A. The participation of the S2 atom in two bonds with the rhenium(I) atom accounts for the disparity in the $\mathrm{C}-$ $\mathrm{S}$ bond lengths, with $\mathrm{C} 1-\mathrm{S} 2$ of 1.778(7) A being considerably longer than $\mathrm{C} 1-\mathrm{S} 1$ of $1.725(7) \AA$. The molecule is disposed about a central $\mathrm{Re}_{2} \mathrm{~S}_{2}$ core which approximates a rectangle. The dithiocarbamate ligands lie to the same side of the core and the separation between the ring centroids is 2.875(3) $\AA$. The observed "syn" conformation of the dithiocarbamate ligands in the title complex matches literature precedents [5-7], with the comparable separations in the $R=[5]$ and $n-B u$ [6] compounds being 2.8813(10) and 2.9177(13) $\AA$, respectively. Such $\pi \cdots \pi$ interactions between chelate rings are well-known in the structural chemistry of metal complexes $[9,10]$. The independent rhenium atom is also coordinated by three terminally bound carbonyl ligands to complete a $\mathrm{C}_{3} \mathrm{~S}_{3}$ donor set. The carbonyl ligands occupy facial positions in the approximately octahedral geometry. The major distortion from a regular octahedral geometry results from the acute chelate angle, $\mathrm{S} 1-\mathrm{Re}-\mathrm{S} 2$ of $70.75(5)^{\circ}$, with the major deviation of a trans angle from the ideal $180^{\circ}$ seen in the C10-Re-S2 angle of 169.9(2) ${ }^{\circ}$.

The molecular packing features methylene- and methyl-C $-\mathrm{H} \cdots \mathrm{O}$ (carbonyl) interactions $\left[\mathrm{C} 5-\mathrm{H} 5 \mathrm{~b} \cdots \mathrm{O} 2^{\mathrm{ii}}\right.$ : $\mathrm{H} 5 \mathrm{~b} \cdots \mathrm{O} 2^{\mathrm{ii}}=2.47 \AA, \quad \mathrm{C} 5 \cdots \mathrm{O} 2^{\mathrm{ii}}=3.359(9) \AA$ with angle at $\mathrm{H} 5 \mathrm{~b}=150^{\circ}$ and $\mathrm{C} 7-\mathrm{H} 7 \mathrm{a} \cdots \mathrm{O} 3^{\mathrm{iii}}$ : $\mathrm{H} 7 \mathrm{a} \cdots \mathrm{O} 3^{\mathrm{iii}}=2.52 \AA$, $\mathrm{C} 7 \cdots \mathrm{O}^{\mathrm{iii}}=3.440(9) \AA$ with angle at $\mathrm{H} 7 \mathrm{a}=156^{\circ}$ for symmetry operations (ii) $1-\mathrm{x}, 1+\mathrm{y}, 1 / 2-\mathrm{z}$ and (iii) $1-\mathrm{x}, 1-\mathrm{y}$, $-z]$. These combine to generate supramolecular layers in the bc-plane. The organic substituents project to either side of the layer, and these stack along the a-axis direction without directional interactions between them.

There are now three $\left\{(\mathrm{CO})_{3} \operatorname{Re}\left[\mathrm{S}_{2} \mathrm{CNR}_{2}\right]\right\}_{2}$ derivatives with all-alkyl dithiocabamate ligands, i.e. $\mathrm{R}=\mathrm{Et}$ [5], $\mathrm{n}-\mathrm{Pr}$ and n-Bu [6], which adopt the same structural motif. All three structures were subjected to an analysis of the Hirshfeld surfaces 
and two-dimensional fingerprint plots (full and delineated) in order to delineate any trends in the molecular packing, at least in terms of prominent contributions to the surface contacts. For this purpose Crystal Explorer 17 [11] was utilised following established procedures [12]. The common feature of the Hirshfeld surface are the significant contributions by $\mathrm{H} \cdots \mathrm{H}$ and $\mathrm{H} \cdots \mathrm{O} / \mathrm{O} \cdots \mathrm{H}$ contacts. A trend appears in the series for $\mathrm{H} \cdot \mathrm{H}$ contacts which increase from the smallest to largest $\mathrm{R}$ substituent, i.e. 20.2, 30.3 and 35.0\%, respectively. This correlates with the greater $\mathrm{H}$ content across the series. The greatest contributions to the Hirshfeld surfaces come from $\mathrm{H} \cdots \mathrm{O} / \mathrm{O} \cdots \mathrm{H}$ contacts. While the percentages are around $40 \%$, no definitive trends are noted in the respective values of 42.5, 37.5 and $40.9 \%$. The next most prominent surface contacts are $\mathrm{H} \cdots \mathrm{S} / \mathrm{S} \cdots \mathrm{H}$ [10.5, 11.0 and 5.8\%] and $\mathrm{H} \cdot \mathrm{C} / \mathrm{C} \cdots \mathrm{H}$ [9.8, 8.9 and 5.6\%]. The percentage contributions in the $\mathrm{R}=\mathrm{Et}$ and $\mathrm{n}$-Pr crystals are about the same but, a notable drop is evident in the $\mathrm{R}=\mathrm{n}$-Bu crystal. A similar trend is noted for $\mathrm{O} \cdots \mathrm{O}$ contacts [5.3, 5.5 and $1.8 \%]$. The only other contacts of note are of the type $\mathrm{C} \cdots \mathrm{O} / \mathrm{O} \cdots \mathrm{C}$ which show a systematic downward trend [7.7,3.6 and 1.8]. As a general comment, as the contribution of the two main surface contacts, i.e. $\mathrm{H} \cdots \mathrm{O} / \mathrm{O} \cdots \mathrm{H}$ and $\mathrm{H} \cdots \mathrm{H}$, systematically increase [62.7, 67.8 and $75.9 \%$, respectvively], there is a fall-off in some of the less significant contributors to the Hirshfeld surface.

Acknowledgements: Sunway University Sdn Bhd is thanked for financial support of this work through Grant no. STRRCTR-RCCM-001-2019.

\section{References}

1. Rigaku Oxford Diffraction. CrysAlis ${ }^{\mathrm{PRO}}$. Rigaku Corporation, Oxford, UK (2018).
2. Sheldrick, G. M.: A short history of SHELX. Acta Crystallogr. A64 (2008) 112-122.

3. Sheldrick, G. M.: Crystal structure refinement with SHELXL. Acta Crystallogr. C71 (2015) 3-8.

4. Farrugia, L. J.: WinGX and ORTEP for Windows: an update. J. Appl. Crystallogr. 45 (2012) 849-854.

5. Lee, S. M.; Lo, K. M.; Heard, P. J.; Tiekink, E. R. T.: Redetermination of the crystal structure of bis $\left(\mu_{2}\right.$-diethyldithiocarbamato- $\left.\mathrm{K}^{3} S, S^{\prime}: S ; \mathrm{K}^{3} S: S: S^{\prime}\right)$-hexacarbonyl-dirhenium(I), $\mathrm{C}_{16} \mathrm{H}_{20} \mathrm{~N}_{2} \mathrm{O}_{6} \mathrm{Re}_{2} \mathrm{~S}_{4}$. Z. Kristallogr. NCS 234 (2019) 719-721.

6. Heard, P. J.; Halcovitch, N. R.; Lee, S. M.; Tiekink, E. R. T.: Crystal structure of bis $\left(\mu_{2}\right.$-di- $n$-butyldithiocarbamato$\left.\mathrm{K}^{3} S, S^{\prime}: S ; \mathrm{K}^{3} S: S: S^{\prime}\right)$-hexacarbonyl-di-rhenium(I), $\mathrm{C}_{24} \mathrm{H}_{36} \mathrm{~N}_{2} \mathrm{O}_{6} \mathrm{Re}_{2}$. Z. Kristallogr. NCS 233 (2018) 485-487.

7. Gorshkov, N. I.; Lumpov, A. A.; Miroslavov, A. E.; Suglobov, D. N.; Katzenellenbogen, J. A.; Luyt, L. G.: "Scorpion-like" dithiocarbamato-carboxylate ligands for linking $\mathrm{M}(\mathrm{CO})_{3}{ }^{+}$ $(M=T c, R e)$. Czech. J. Phys. (2003) 53 A543-A548.

8. Tiekink, E. R. T.: Exploring the topological landscape exhibited by binary zinc-triad 1,1-dithiolates. Crystals 8 (2018) 292 (34 pages).

9. Malenov, D. P.; Janjić, G. V.; Medaković, V. B.; Hall, M. B.; Zarić, S. D.: Noncovalent bonding: stacking interactions of chelate rings of transition metal complexes. Coord. Chem. Rev. 345 (2017) 318-341.

10. Tiekink, E. R. T.: Supramolecular assembly based on "emerging" intermolecular interactions of particular interest to coordination chemists. Coord. Chem. Rev. 345 (2017) 209-228.

11. Turner, M. J.; Mckinnon, J. J.; Wolff, S. K.; Grimwood, D. J.; Spackman, P. R.; Jayatilaka, D.; Spackman, M. A.: Crystal Explorer v17. The University of Western Australia, Australia (2017).

12. Tan, S. L.; Jotani, M. M.; Tiekink, E. R. T.: Utilizing Hirshfeld surface calculations, non-covalent interaction ( $\mathrm{NCl}$ ) plots and the calculation of interaction energies in the analysis of molecular packing. Acta Crystallogr. E75 (2019) 308-318. 